\title{
Hek293 as a recombinant protein factory: three different approaches for protein production
}

\author{
Leticia Liste-Calleja ${ }^{1 *}$, Martí Lecina', Roland Schucht ${ }^{2}$, Dagmar Wirth ${ }^{3}$, Hansjörg Hauser $^{4}$, Jordi J Cairó ${ }^{1}$ \\ From 24th European Society for Animal Cell Technology (ESACT) Meeting: C2P2: Cells, Culture, Patients, Products \\ Barcelona, Spain. 31 May - 3 June 2015
}

\section{Background}

Recombinant products have reached the market in diverse areas, including pharmaceutical, veterinary food, pesticides and detergents. Noteworthy, approximately 30 recombinant products in the pharmaceutical sector account for more than 90 per cent of all recombinant product sales. Although microbial systems can be considered an attractive option for expressing certain biopharmaceutical proteins, many biopharmaceutical molecules are too large and complex and need to be expressed in mammalian cells.

The most reported cell lines used for industrial processes are $\mathrm{CHO}, \mathrm{NS} 0, \mathrm{Sp} 2 / \mathrm{O}-\mathrm{Ag} 14$ and HEK293. In particular, the latter has been gaining significant importance in the biopharmaceutical field during the last two decades. While initially employed for adenoviral vector production HEK293 became also one of the preferred cell lines for transient or stable protein expression. This is mainly due to its high transfection efficiency. Meanwhile genetic manipulation also includes new techniques for directing the integration of the foreign gene to highly expressed chromosomal sites e.g. by RMCE.

In this work, three strategies for recombinant protein production in HEK293 cells have been compared (Figure 1): (St.1) rAdV production expressing protein of interest, (St.2) stable cell line establishment by random gene transfection or (St.3) site-specific integration using RMCE technology. As protein of interest we used the Cap protein from the capsid of porcine circovirus serotype 2 (CAP-PCV2). This virus is related to post weaning multisystemic wasting syndrome (PMWS), which has major implications for the pig industry worldwide.

${ }^{1}$ Chemical Engineering Department, Universitat Autònoma de Barcelona, Barcelona, Spain

Full list of author information is available at the end of the article

\section{Materials and methods}

\section{Strategy 1. CapPCV2 recombinant Adenovirus}

Viral DNA was isolated from field and the gene of the capsid (CapPCV2) was cloned into Adh5 genome using AdEasyXL kit. Virus and protein production were performed by infecting HEK293-F6 suspension cells [1].

Strategy 2. HEK293 stable cell line by random integration CapPCV2 gene sequence was codon optimized for mammalian cell expression. The obtained sequence was cloned into pIRESpuro3 bicistronicvector [2]. HEK293F6 suspension cells were transfected (PEI-DNA method) and positive cell pool was selected by puromycin addition to the media.

\section{Strategy 3. HEK293 stable cell line by RMCE}

Three targeting vectors encoding for different promoters were transfected by electroporation to three different HEK293 master cell lines. Positive clones were selected by neomycin and ganciclovir addition to media. Clones were isolated by single colony pick up. Upon the selection of the best promoter, RMCE was applied to 293T cell line [3]. Positive clones were selected by puromycin addition to media and single colony isolation was carried out. The selected clone was finally adapted to grow in suspension.

\section{Results}

We generated transient Cap-PCV2 producer cells by infection of the HEK293 cell line with a recombinant adenovirus (rAdV-Cap) (Figure 1, left panel). This approach gave a specific production (qp) of (41.291 \pm $0.0002) \mathrm{e}-3 \mathrm{pg} / \mathrm{cell}$, which is considerably low (Table 1 ).

In contrast, a significant increase in production was achieved upon random integration of a CapPCV2 encoding plasmid (Figure 1B) which resulted in a 2.5 fold increment of qp $(0.107 \pm 0.018 \mathrm{pg} / \mathrm{cell})$. The best results were obtained upon the site directed integration 


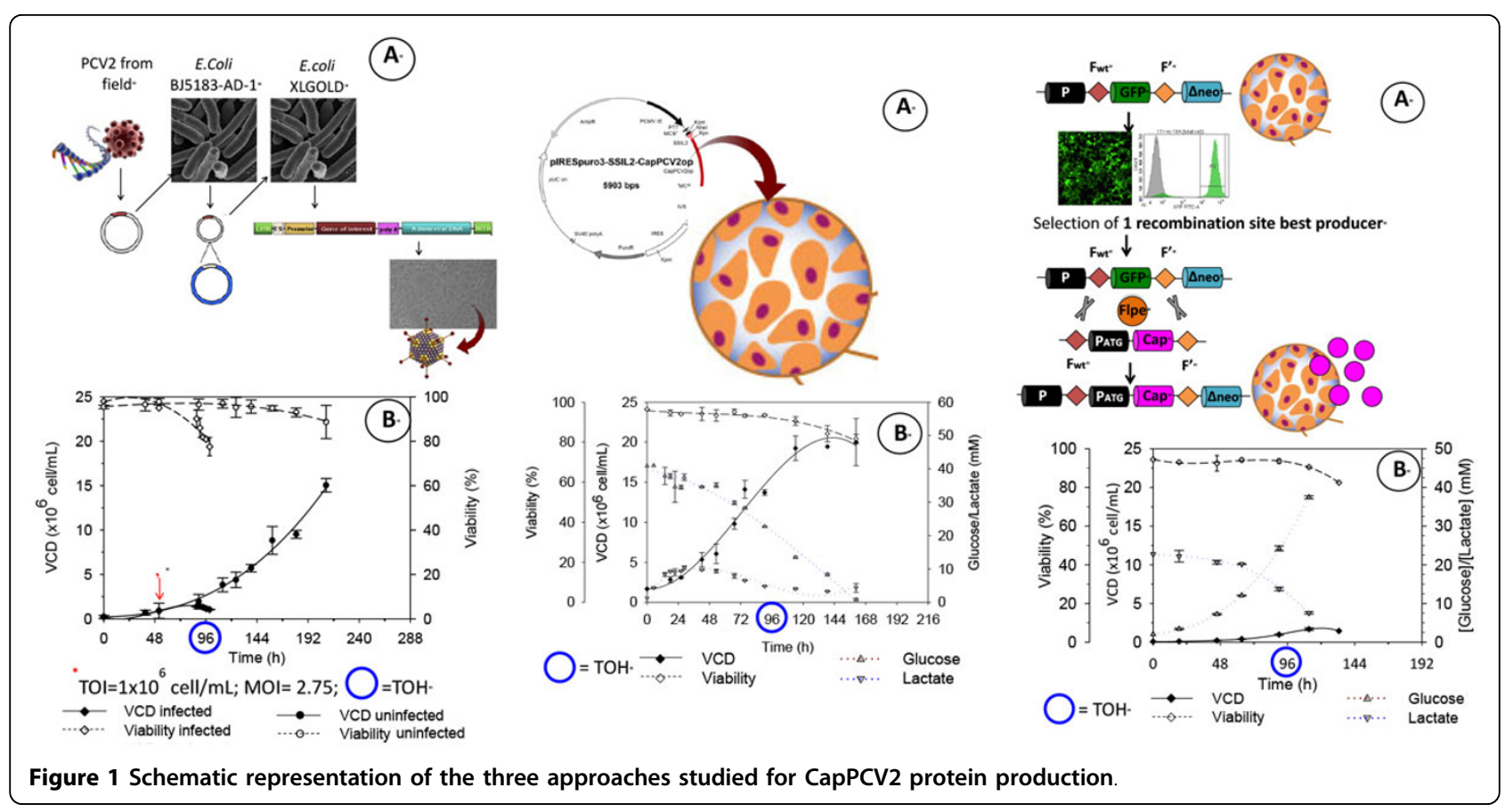

Table 1. Values of significant process production parameters

\begin{tabular}{llll}
\hline & $\begin{array}{l}\text { Specific production } \\
\text { (pg/cell) }\end{array}$ & $\begin{array}{l}\text { [CapPCV2] } \\
\text { (ng/mL) }\end{array}$ & $\begin{array}{l}\text { Volumetric productivity } \\
\text { (ng/(mL·day)) }\end{array}$ \\
\hline Adenoviral infection & $(41.291 \pm 0.0002) \mathrm{e}^{-3}$ & $20.85 \pm 0.84$ & $9.25 \pm 0.60$ \\
Illegitimate integration & $0.107 \pm 0.018$ & $327.34 \pm 62.53$ & $103.14 \pm 8.6$ \\
Site-directed integration & $0.226 \pm 0.034$ & $256.57 \pm 21.28$ & $64.11 \pm 0.13$ \\
\hline
\end{tabular}

using RMCE technology (Figure 1C). Using this approach, CapPCV2 gene was inserted into previously identified chromosomal hotspots. The specific production of the RMCE-derived stable cell line $(0.226 \pm 0.034$ $\mathrm{pg} / \mathrm{cell}$ ) doubled the one of the cell line obtained by illegitimate integration. Nevertheless, the highest volumetric productivity was calculated for the stable cell line after illegitimate integration $(103.14 \pm 8.6 \mathrm{ng} /(\mathrm{mL} \cdot$ day $))$. This is related to the capacity of this cell line to grow in suspension in contrast to the adherent cell growth of the RMCE-derived cell line. The high cell densities achieved in cell suspension culture ( $\approx 18 \mathrm{e} 6 \mathrm{cell} / \mathrm{mL})$ [4] can compensate the lower qpof the cell line.

\section{Conclusions}

The main conclusion of this work is that a bioprocess based on site-integrated stable suspension cell line would be the preferred one not only because the highest qp, but also due to the easy characterization of the process (in comparison to adenovirus infection), the repeatability of batch productions (in comparison to the other approaches) and the possibility of rapid substitution of the protein of interest.

\section{Authors' details}

${ }^{1}$ Chemical Engineering Department, Universitat Autònoma de Barcelona, Barcelona, Spain. ${ }^{2}$ InSCREENeX GmbH, Braunschweig, Germany. ${ }^{3}$ Model Systems for Infection and Immunity, Helmholtz Center for Infection Research, Braunschweig, Germany. ${ }^{4}$ Dept. of Gene Regulation and Differentiation, Helmholtz Center for Infection Research, Braunschweig, Germany.

Published: 14 December 2015

\section{References}

1. Coté J, Garnier A, Massie B, Kamen A: Serum-free production of recombinant proteins and adenoviral vectors by $293 \mathrm{~F}-3 \mathrm{~F} 6$ cells. Biotechnology and Bioengineering 1998, 59:567-575.

2. Niwa H, Yamamura K, Miyazaki J: Efficient selection for high-expression transfectants with a novel eukaryotic vector. Gene 1991, 108:193-9.

3. Schucht R, Coroadinha AS, Verhoeyen E, Carrondo MJT, Hauser H, Wirth D: A new generation of retroviral producer cells: predictable and stable virus production by Flp-mediated site-specific integration of retroviral vectors. Molecular Therapy 2006, 14:285-292.

4. Liste-Calleja L, Lecina M, Cairó JJ: HEK293 cell culture media study towards bioprocess optimization: Animal derived component free and animal derived component containing platforms. Journal of Bioscience and Bioengineering 2014, 117:471-477.

doi:10.1186/1753-6561-9-S9-P74

Cite this article as: Liste-Calleja et al.: Hek293 as a recombinant protein factory: three different approaches for protein production. $B M C$ Proceedings 2015 9(Suppl 9):P74. 